\title{
Study of Mechanical and Tribological Properties of Nanomica Dispersed Hydroxyapatite Based Composites for Biomedical Applications
}

\author{
Anumeha Mishra, ${ }^{1}$ Nidhi Khobragade, ${ }^{1}$ Koushik Sikdar, ${ }^{1}$ Subhabrata Chakraborty, ${ }^{2}$ \\ Sashi Bhusan Kumar, ${ }^{1}$ and Debdas Roy ${ }^{1}$ \\ ${ }^{1}$ Department of Materials and Metallurgical Engineering, NIFFT, Ranchi 834003, India \\ ${ }^{2}$ Department of Chemical Engineering, NIT, Rourkela 769008, India \\ Correspondence should be addressed to Debdas Roy; droy2k6@gmail.com
}

Received 8 December 2016; Accepted 24 January 2017; Published 26 February 2017

Academic Editor: Charles C. Sorrell

Copyright (C) 2017 Anumeha Mishra et al. This is an open access article distributed under the Creative Commons Attribution License, which permits unrestricted use, distribution, and reproduction in any medium, provided the original work is properly cited.

\begin{abstract}
Present research aims to assess the influence of nanocrystalline mica (NM) dispersion (10, 15, 20, and 25 vol.\%) in hydroxyapatite (HA) matrix on its mechanical and tribological properties and bioactivity. Nanosized mica (NM) was prepared by mechanical milling of commercial mica powder. The composite was prepared by mechanically mixing the milled mica with HA and consolidated by microwave sintering at $1200^{\circ} \mathrm{C}$ for $10 \mathrm{~min}$. Phase characterization by X-ray diffraction (XRD) shows dissociation of HA into $\beta$-TCP (tetra calcium phosphate) in sintered compact. Estimated densification is the highest ( 98\%) with $20 \%$ NM addition. HA$20 \% \mathrm{NM}$ also shows an optimum combination of mechanical (hardness $2.80 \mathrm{GPa}$ and indentation fracture toughness $1.51 \mathrm{MPa}^{1 / 2}$ ) and tribological properties (wear rate $\sim 1.6 \times 10^{-6} \mathrm{~mm}^{3} / \mathrm{Nm}$ ). Scanning electron microscopy (SEM) of worn out surface elicits that wear mechanism is governed mainly by delamination and abrasive mode. Biocompatibility assessment in simulated body fluid (SBF) indicates that no elemental change occurs (confirmed by energy dispersive spectroscopy (EDS)) even after 60 days of emersion. It reveals that the optimized composition is satisfying fundamental requirements of an implant material.
\end{abstract}

\section{Introduction}

Hard orthopedic implant materials, especially which can replace bone tissues for compensating traumatic or nontraumatic injuries have drawn an overwhelming research interest. However, stringent compatibility requirements are major constraints for developing orthopedic implant materials for biomedical applications, especially for replacement, support, and supplementary functions of the living tissues of human body $[1,2]$. Hydroxyapatite (HA) $\left(\mathrm{Ca}_{10}\left(\mathrm{PO}_{4}\right)_{6}(\mathrm{OH})_{2}\right)$ is the major available inorganic component with biocompatibility, bioactivity, and osteoconductive properties. It is extensively applied for dental and skeleton implants, bone repair scaffolds, and body insert materials [3-5]. Except bone tissue related applications, HA is also used for tissue repair and replacement and also for implant osseointegration [6]. However, major limitation of its monolithic application is attributed by its low fracture toughness and fracture strength $\left(0.8-1.2 \mathrm{MPa} \mathrm{m}^{1 / 2}\right.$ and $<120 \mathrm{MPa}$, resp.) in comparison to natural human bone (2-12 MPa $\mathrm{m}^{1 / 2}$ and $\sim 150 \mathrm{MPa}$, resp.) [7]. Thus, for compensating inherited brittleness, $\mathrm{HA}$ is usually reinforced with second phases like $\mathrm{Al}_{2} \mathrm{O}_{3}, \mathrm{ZrO}_{2}$, $\mathrm{TiO}_{2}$, and so forth without affecting its biocompatibility [8, 9]. Wen et al. [10] reported that $\mathrm{HA} / \mathrm{TiO}_{2}$ coating (by sol gel method) on TiZr alloy improves bond between living tissue and implant. Their work revealed that $\mathrm{Ca}: \mathrm{P}$ ratio increased to 1.67 due to dissolution of $\mathrm{OH}^{-}$and $\mathrm{PO}^{3-}$ ions from coating. It combines with $\mathrm{Ca}^{2+}$ ions after soaking in SBF for 15 days, showing good bioactive property. Incorporation of $\mathrm{HA}$ in $\mathrm{Mg}$ has improved the compressive strength (from 
132.7 $\mathrm{MPa}$ to 191.40 MPa) and modulus (from 22.9 GPa to $35.80 \mathrm{GPa}$ ) of HA-Mg composites [11]. Furthermore, HA addition in $\mathrm{Mg}$ also significantly reduces hydrogen evolution and localized $\mathrm{pH}$ variation during in vitro degradation and thereby enhances mechanical and biological performances of composite. Researchers also reported that the addition of $\mathrm{Ag}$ particles in HA matrix exhibited enhanced hardness, densification, and antimicrobial properties as compared to pure HA [12]. Nath et al. [13] reported that when $30 \%$ mullite was added to $\mathrm{HA}$, it decomposed into secondary phosphate phase $\left(\beta\right.$-TCP) at $1200^{\circ} \mathrm{C}$ sintering temperature. Nanosized dispersion of partially stabilized zirconia (PSZ) particles in HA matrix was reported to have the highest value of microhardness $9.3 \mathrm{GPa}$ with $30 \%$ addition of PSZ [14]. Again, with such dispersion the coefficient of friction also reduced by lubricating condition provided by ceramic particles [14]. During solid state processing $\mathrm{HA}-\mathrm{ZrO}_{2}$ composites decomposes and forms $\beta$-TCP, $\mathrm{CaO}, \mathrm{t}-\mathrm{ZrO}_{2}$, and $\mathrm{CaZrO}_{3}$ [8]. The formation of secondary phases affects the sinterability of green compact due to differential shrinkage, resulting in poor densification as compared to sintered pure HA. Farzin et al. [15] prepared dense nanostructured and microstructured $\mathrm{HA}-\mathrm{TiO}_{2}$ composite by consolidating conventional and twostep sintering method. This nanostructured $\mathrm{HA}-\mathrm{TiO}_{2}$ exhibits excellent cell viability within 5-diphenyl tetrazolium bromide solution (MTT) by promoting osteoblast proliferation [15]. Dispersion of $\mathrm{Al}_{2} \mathrm{O}_{3}$ in $\mathrm{HA}$ matrix enhances the fracture toughness from 1.18 $\mathrm{MPa} \mathrm{m}^{1 / 2}$ to $2.07 \mathrm{MPa} \mathrm{m}^{1 / 2}$ which again bolstered by synergistic action of carbon nanotube addition to reach the fracture toughness of resulting composite to $\sim 2.3$ times of parent HA [16]. The HA-Ti composites prepared by spark plasma sintering (SPS) with varying Ti concentration (5, 10 and 20\%) show the high fracture toughness (4$5 \mathrm{MPa} \mathrm{m}^{1 / 2}$ ) with a good combination of elastic modulus $(50 \mathrm{GPa}-58 \mathrm{GPa})$ and flexural strength $(79 \mathrm{MPa}-99.7 \mathrm{MPa})$ [17]. Mica is one of the naturally occurring mineral having high strength, good corrosion resistance, and thermal stability [18-20]. Inherited brittleness of HA was reported to be mitigated by reinforcing strong mica sheets or fibers [21]. When mica is reinforced in HA, the major portion of stress is transmitted to dispersoids, thereby enhancing its mechanical properties $[21,22]$. In the present work nanomica was prepared by mechanical milling; it was then mixed (10-25 wt.\%) with HA mechanically. Composite was then prepared by subjecting the powder blend under microwave sintering. In order to optimize the influence of volume fraction of NM addition, its mechanical property was measured. Finally, the optimized composition was subjected to wear testing and biocompatibility assessment.

\section{Experimental Procedure}

2.1. Powder Preparation. In present work, hydroxyapatite (HA) powder has been prepared by suspension precipitation method. Initially calcium oxide $(\mathrm{CaO})$ was dispersed in distilled water, kept on hot plate, and magnetically stirred.
After that $\mathrm{H}_{3} \mathrm{PO}_{4}$ was added into the solution by keeping $\mathrm{Ca} / \mathrm{P}$ ratio similar to $\mathrm{HA}$. Finally solution was heated to $80^{\circ} \mathrm{C}$ and stirred for 3-4 h to form synthesized HA. Ammonia $\left(\mathrm{NH}_{4} \mathrm{OH}\right)$ was then added to the solution to increase $\mathrm{pH}$ to 10. Final solution was then left for one day for precipitation, which was collected subsequently by filtering. Obtained powder was then dried and calcined at $800^{\circ} \mathrm{C}$. Mica powder was synthesized from commercially available micron sized powders of mica (99\% Pure, LOBA Chemic Pvt Ltd, Mumbai) by milling. The milling was performed in a planetary ball mill (FRITSCH, Germany). Initially the particle size of the mica was measured with the help of a particle size analyzer (FRITSCH Particle Sizer Annlysett-22). After milling for a predetermined time of $6 \mathrm{~h}$ ball-milled powder was taken out for analysis.

2.2. Composite Preparation. The mica powder was dry milled for 6 hours and particle size was analyzed to ensure nanocrystalline formation. The composites for present investigation was prepared by mechanically mixing the ball milled nanomica in varying proportion (10-25 wt\%) with $\mathrm{HA}$ in wet medium (acetone) into a vial by using tungsten carbide ball as mixing media. The ball to powder weight ratio was maintained at $10: 1$. The HA-NM (10-25\%) ball milled powder was consolidated by microwave sintering method at $1200^{\circ} \mathrm{C}$ for $10 \mathrm{~min}$.

\subsection{Phase and Microstructural Characterization of Sintered} Composite. The phase analysis of milled and sintered samples was performed using PANalytical $3 \mathrm{~kW}$ X'pert Powder XRD, Multifunctional instrument with $\operatorname{CuK} \alpha(\lambda=0.1541 \mathrm{~nm})$ source of incident radiation with the potential $30 \mathrm{kV}$ and current $20 \mathrm{~mA}$. The analysis was recorded in the $2 \theta$ range of $20^{\circ}$ to $80^{\circ}$ at a scanning rate of $0.02^{\circ} / \mathrm{min}$. The microstructural investigation of sintered samples was done by using ZEISS EVO Series Scanning Electron Microscope Model EVO 18 instrument. Microstructural characterization of synthesized HA and milled nanomica powder was also carried out by using transmission electron microscopy ((FEI Tecnai TF30 G2 Super Twin, with Bruker EDS Detector) with beam energy of $300 \mathrm{keV}$. Figures 1(a) and 1(b) show the TEM image of milled NM powder and its elemental distribution, respectively, and also image of as prepared $\mathrm{HA}$ powder in Figure 1(c).

2.4. Mechanical and Tribological Characterization. The microhardness of sintered pellets was measured by SIMANDZU Semi-Automatic Micro Vickers hardness tester. The microhardness test was carried out using $100 \mathrm{~g}$ load with a dwell time of $15 \mathrm{sec}$ for each 10 indents taken to get the average value. The microhardness of the indent is calculated by using the following formulae:

$$
H v=1.854 \frac{F}{d^{2}},
$$




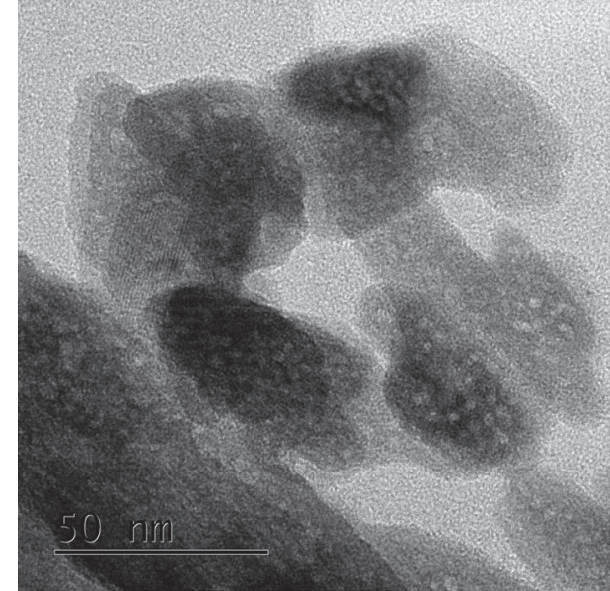

(a)

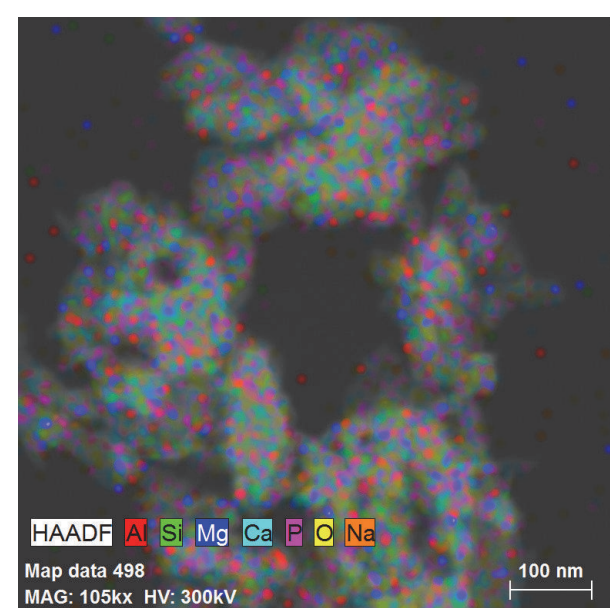

(b)

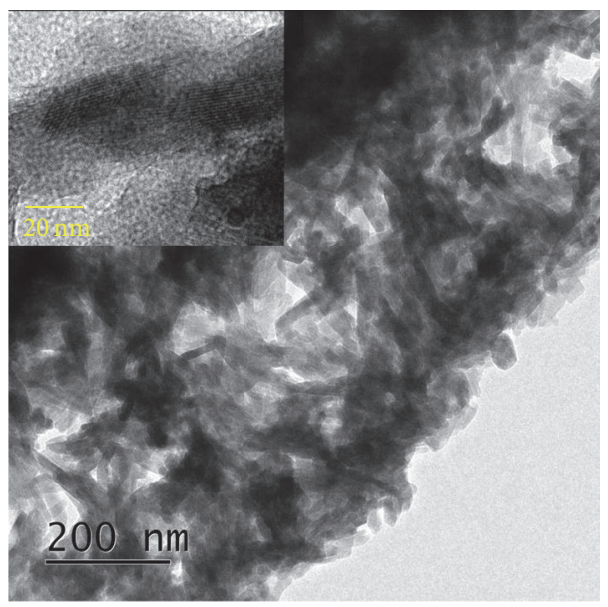

(c)

FIGURE 1: Starting material. (a) Milled nanosized mica, (b) elemental distribution in milled mica, and (c) as prepared HA powder.

where $H v$ is the value of microhardness, $F$ is the applied load (kg-f), and $d$ is the diagonal indent length $(\mathrm{mm})$. Indentation fracture toughness of sintered composites was estimated by using the diagonal crack lengths at the corners of the indentation during the microindentation testing. Fracture toughness was calculated by [23]

$$
K_{I C}=0.16 H V a^{1 / 2}\left(\frac{a}{c}\right)^{-3 / 2},
$$

where $K_{I C}$ is the fracture toughness in $\mathrm{MPa} \cdot \mathrm{m}^{1 / 2}, \mathrm{Hv}$ is the Vickers microhardness ( $\mathrm{GPa}), a$ is the half-diagonal of the indentation in $\mathrm{mm}$, and $c$ is the half-distance between the opposite crack tips in $\mathrm{mm}$.

Tribological behavior of composites was evaluated using a zirconia ball counterbody on reciprocating fretting wear tester. The frequency was kept constant for all samples at $5 \mathrm{~Hz}$. The wear test was carried out at constant load of $5 \mathrm{~N}$ with $10^{3}$ cycles for all different samples.
2.5. Weight Loss Study in Simulated Biological Fluid. To study the bioactivity of synthesized composites the dissolution study in simulated body fluid (SBF) was carried out. The composition to prepare artificial simulated body fluid was proposed by Kokubo et al. [24]. The chemical reagents used to prepare simulated body fluid are almost $99 \%$ pure. The composition and concentration of simulated bold fluid solution are prepared by using different chemicals like $\mathrm{NaCl}, \mathrm{KCl}$, $\mathrm{K}_{2} \mathrm{HPO}_{4} \cdot 3 \mathrm{H}_{2} \mathrm{O}, \mathrm{MgCl}_{2} \cdot 6 \mathrm{H}_{2} \mathrm{O}, \mathrm{CaCl}_{2}$, and $\mathrm{Na}_{2} \mathrm{SO}_{4}$ in distilled water and $\mathrm{pH}$ with tris (hydroxymethyl), aminomethane, and $\mathrm{HCl}$. The required chemical reagents were mixed in distilled water using magnetic stirrer at a temperature of $60^{\circ} \mathrm{C}$ with a speed of $40 \mathrm{rpm}$ for $30 \mathrm{~min}$. The sintered samples were immersed in SBF for 1, 7, and 60 days. After each immersion period the samples were removed from SBF solution, washed with deionized water and acetone, and dried at room temperature. The surface morphology and elemental composition of HA-nanomica after immersion in SBF were studied by SEM and EDS analysis. 


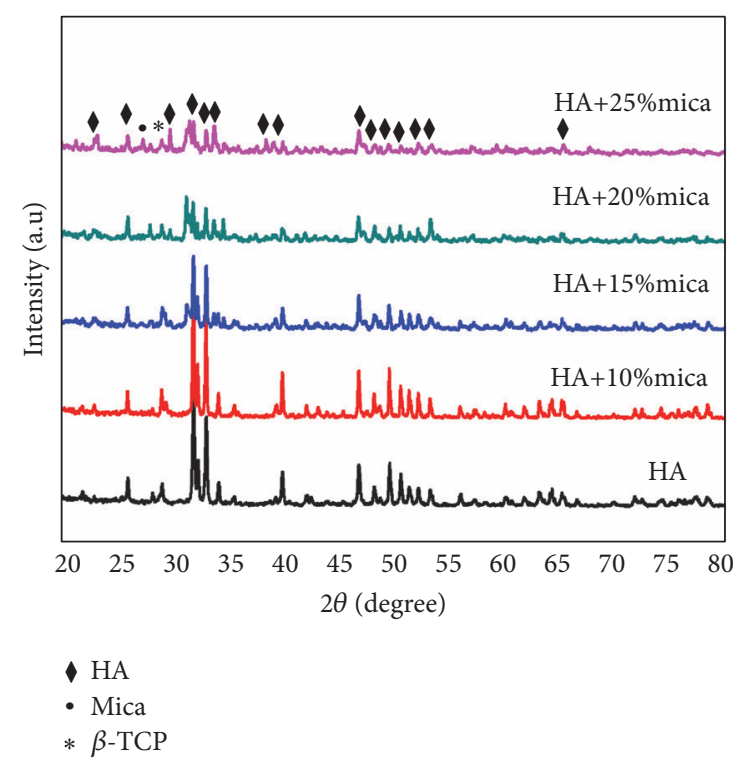

FIGURE 2: XRD pattern of HA-nanomica composite by microwave sintering.

\section{Results and Discussion}

Figure 2 shows the XRD profiles of pure HA and HA-NM $(10,15,20$, and 25 vol. $\%)$ composites after sintering. The XRD spectrum shows the strong peaks of pure HA without NM addition. However, with increase in NM content HA peak intensity decreases and additional peaks of $\beta$-TCP appear. Present result is streamlined with previous investigations where thermal dissociation of HA was attributed the reason of $\beta$-TCP formation $[25,26]$. In addition to this, small traces of mica are noticeable throughout the compositional range. The similar diffraction peaks of HA and mullite composites are observed by Dubey et al. [26] with 20\% mullite content consolidated at $1200^{\circ} \mathrm{C}$ by spark plasma sintering technique. Dasgupta et al. [27] also reported that the microwave sintered pure HA powder $\left(\right.$ at $1150^{\circ} \mathrm{C}$ ) shows only diffraction peaks corresponding to HA without formation of any secondary phases.

The microstructural features of pure HA and HA-NM composites were observed using SEM. Figure 3(a), the microstructure of pure HA with presence of porosity and nanosized grains whereas Figures 3(b)-3(e) display the microstructure of $\mathrm{HA}-10 \%$ to $25 \%$ NM, respectively. The microstructural features of HA-10\%NM composite show less porosity as compared to pure HA. The microstructure appears to be dense and less porous in $\mathrm{HA}-15 \% \mathrm{NM}$ and $\mathrm{HA}-20 \% \mathrm{NM}$, respectively. Here, the nanomica particles are distributed throughout the matrix. In Figure 3(e) the microstructure of $25 \%$ NM content shows the more pores as compared to other microstructures which affects the relative density of the sample (see Table 1). The plastic flow during sintering is evident (Figure 3(f)).

Relative density, hardness, and indentation fracture toughness of the composite are presented in Table 1. It is clear that the relative density increases with NM content. Density of $\mathrm{HA}-10 \% \mathrm{NM}$ is $96.20 \%$ which increases up to $98 \%$ with $20 \%$ NM dispersion. However, the density of the composite does not improve on further increase (say 98\% for $25 \%$ $\mathrm{NM}$ ) in NM dispersion; this is in agreement with the earlier reported results in the literature [28-30]. For HA-20\%NM higher relative density is owing to minimum porosity content. Formation of porosity can be attributed to different shrinkage of parent phase (HA) and product $\beta$-TCP phase (shown in XRD, Figure 2). Dehydroxylation of HA leads to formation of $\beta$-TCP during sintering by the following reaction $[25,26]$ :

$$
\mathrm{Ca}_{10}\left(\mathrm{PO}_{4}\right)_{6}(\mathrm{OH})_{2} \longrightarrow 3 \mathrm{Ca}_{3}\left(\mathrm{PO}_{4}\right)_{2}+\mathrm{CaO}+\mathrm{H}_{2} \mathrm{O} \uparrow
$$

The microhardness value of $\mathrm{HA}-10 \% \mathrm{NM}$ shows hardness of $\sim 2.10 \mathrm{GPa}$ which increases to $\sim 2.80 \mathrm{GPa}$ up to $20 \% \mathrm{NM}$ addition. With further increase in NM content (say 25 vol.\%) resulting composite shows a comparatively lower value of hardness $(\sim 2.55 \mathrm{GPa})$, which may be attributed to agglomeration of NM particles in microwave sintered composites. Dubey et al. [26] observed the Vickers hardness in between 3.2 and $7.2 \mathrm{GPa}$ by spark plasma sintered $\left(1050-1100^{\circ} \mathrm{C}\right) \mathrm{HA}-$ mullite composites. The indent image of microwave sintered composites shown in Figure 4(a). The fracture toughness of $10 \% \mathrm{NM}$ is $1.31 \mathrm{MPa} \cdot \mathrm{m}^{1 / 2}$ which increases up to $1.51 \mathrm{MPa} \cdot \mathrm{m}^{1 / 2}$ for $20 \% \mathrm{NM}$ addition in HA matrix. The fracture toughness of HA-25\%NM decreases to $1.43 \mathrm{MPa} \cdot \mathrm{m}^{1 / 2}$ due to decrease in hardness. SEM micrograph of 25\% NM content (Figure 4(e)) shows NM agglomeration in HA matrix, presumably responsible for detrition of mechanical properties say microhardness and indentation fracture toughness. As mechanical properties degrade when reinforcement $>20 \%$, we continued further investigations for $20 \% \mathrm{NM}$ only.

The interactions of a crack path with microstructural features are shown in representative SEM images of HA20NM composite (Figure 4). In Figure 4(a), the crack arising from the Vickers indent is shown. A wavy nature of crack path is visible, as marked by a series of arrows (Figure 4(b)). Clearly, the crack goes along the grain boundaries or is deflected and/or bridged by elongated second phase particles on its propagation (Figures $4(\mathrm{c})$ and $4(\mathrm{~d})$ ).

Coefficient of friction (COF) is the ratio of tangential force $\left(F_{t}\right)$ to normal load $\left(F_{N}\right)$ [31]. The experimentally observed variations of coefficient of friction (COF) against the number of cycles in HA-NM composites under ambient condition are shown in Figures 5(a) and 5(b). Data obtained for the particular test condition (say $5 \mathrm{~N}$ load, $5 \mathrm{~Hz}$ frequency, $10^{3}$ cycles) refers that COF can be distinguished into three (3) distinct segments say running-in period, intermediate region, and steady state region (see Figure 5(a)). In running in period $(\sim 100$ cycles) value of COF is minimum (see Figure 5(b)). Most probable reason is less asperity contact as the test duration is short. With increase in number of cycles, COF increases sharply and reaches a steady state. Increase in asperity contacts with time/number of cycles was attributed to this initial rise in COF. As asperities equilibrate 
TABLE 1: Density, hardness, and fracture toughness of HA-nanomica composites.

\begin{tabular}{lccc}
\hline Composition & Relative density $(\%)$ & Vickers hardness $(\mathrm{GPa})$ & Indentation fracture toughness $\left(\mathrm{MPam}^{1 / 2}\right)$ \\
\hline HA-10\%nanomica & 96.20 & 2.10 & 1.31 \\
HA-15\%nanomica & 97.65 & 2.35 & 1.4 \\
HA-20\%nanomica & 98.00 & 2.80 & 1.51 \\
HA-25\%nanomica & 97.80 & 2.55 & 1.43 \\
\hline
\end{tabular}

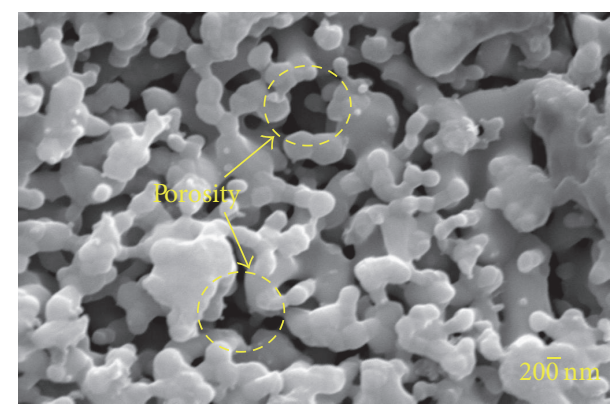

(a)

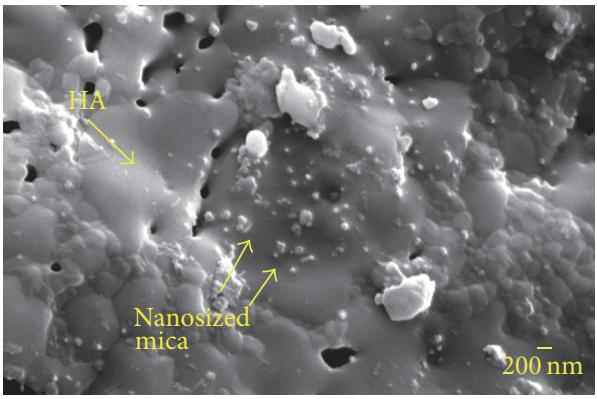

(c)

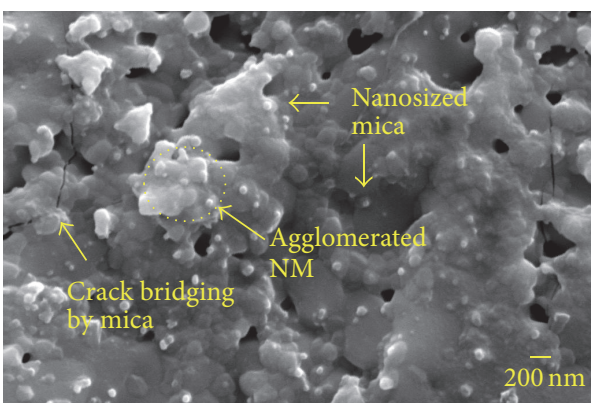

(e)

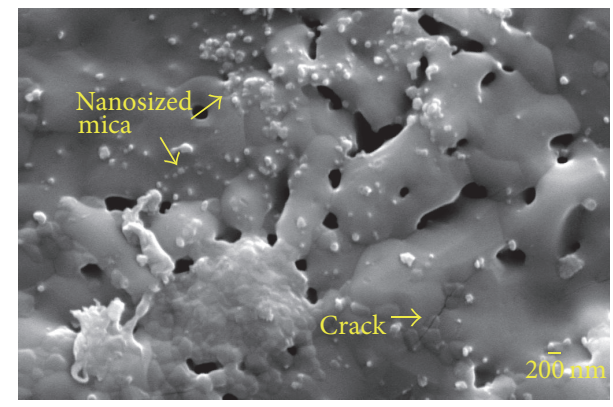

(b)

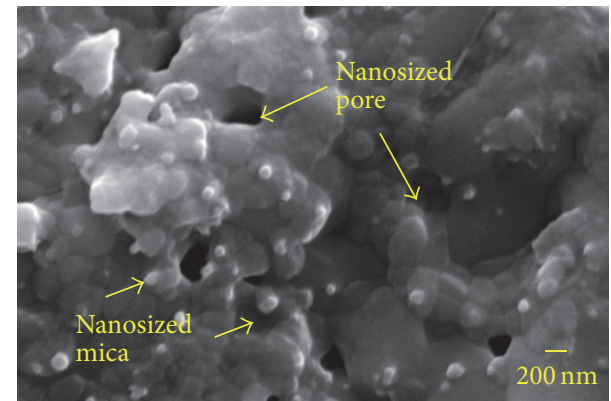

(d)

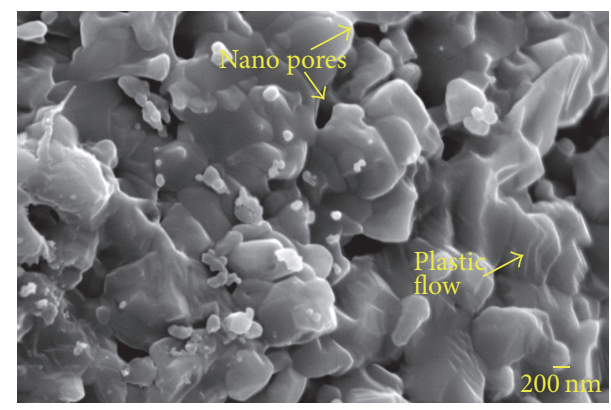

(f)

FIGURE 3: SEM images of (a) pure HA, (b) HA-10\%nanomica, (c) HA-15\%nanomica, (d) HA-20\%nanomica, and (e) HA-25\%nanomica composites. (f) High magnification image showing plastic flow responsible for densification during sintering.

out, COF reaches a steady state. Under steady state HA$20 \% \mathrm{NM}$ composite shows minimum COF value ( 0.4). At steady state the COF values depict the following trend:

$$
\begin{aligned}
\text { Pure } \mathrm{HA} & \approx \mathrm{HA}-10 \mathrm{NM} \approx \mathrm{HA}-15 \mathrm{NM} \approx \mathrm{HA}-25 \mathrm{NM} \\
& >\mathrm{HA}-20 \mathrm{NM}
\end{aligned}
$$

Measured values of wear rates are plotted in Figure 6. Superior wear resistance is observed for HA-20NM composite $\left(1.6 \times 10^{-6} \mathrm{~mm}^{3} / \mathrm{Nm}\right)$ when compared to pure HA $(8 \times$ $\left.10^{-6} \mathrm{~mm}^{3} / \mathrm{Nm}\right)$. Superior wear resistance was presumable due to its higher hardness and fracture toughness $(2.8 \mathrm{MPa}$ and $1.51 \mathrm{MPam}^{1 / 2}$ ) owing to least porosity ( 2\%). The porosity of the HA-based composites was obtained by quantitative image analysis. 


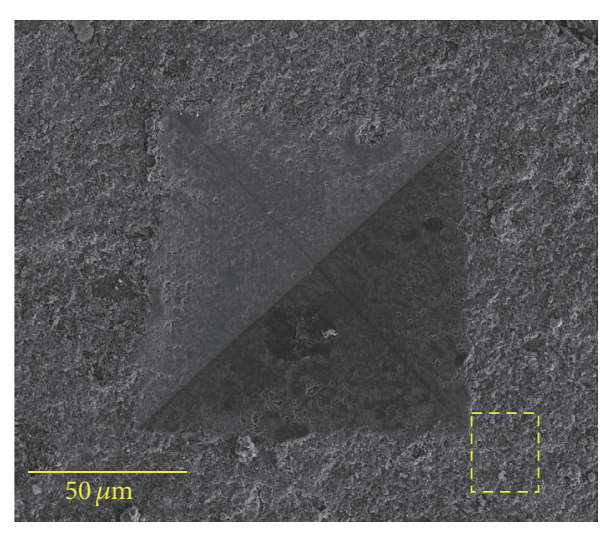

(a)

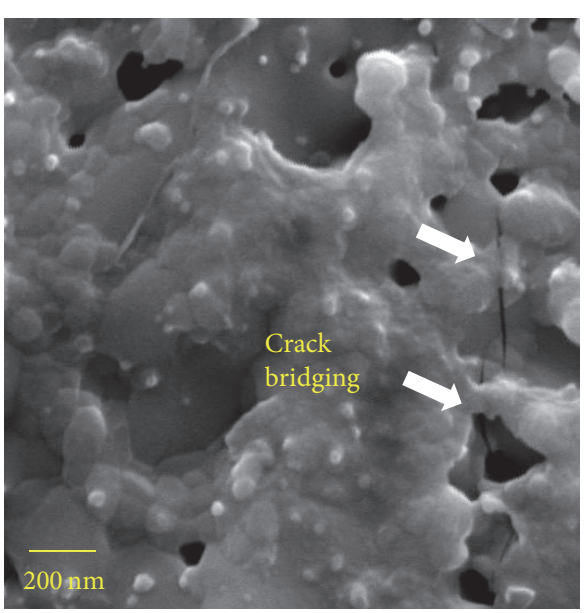

(d)

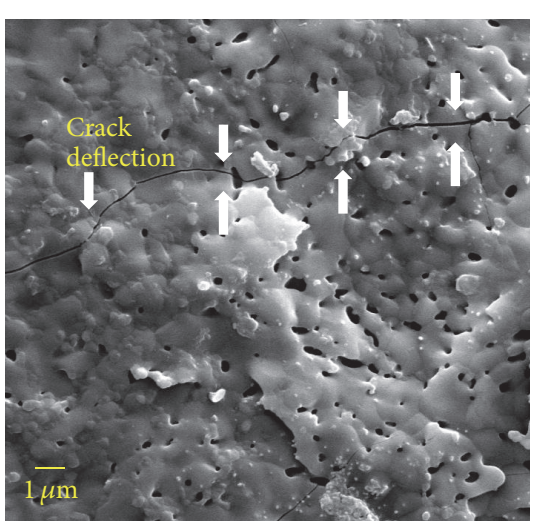

(b)

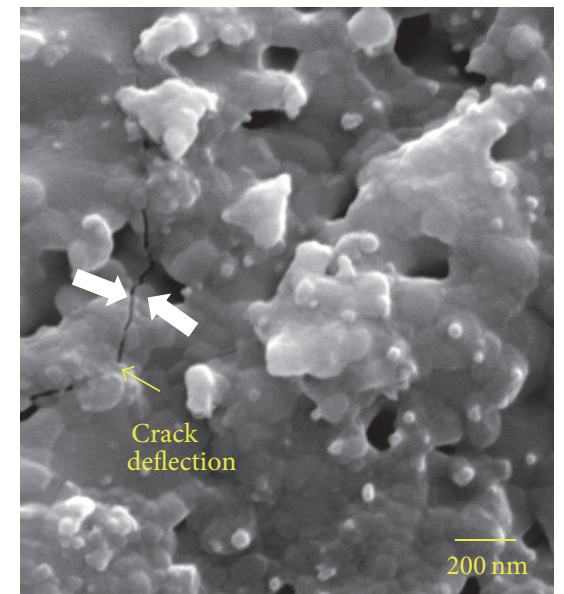

(c)

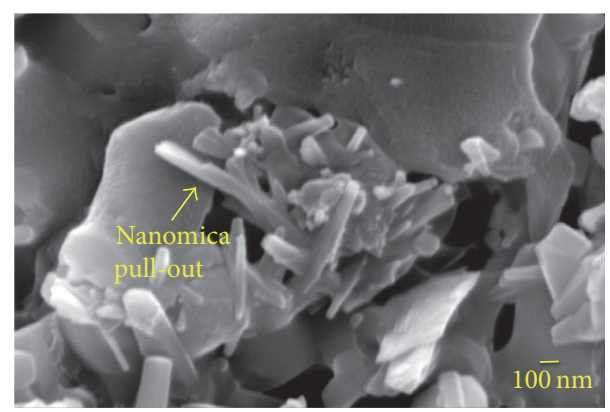

(e)

FIGURE 4: Representative SEM micrographs of indent image of (a) HA-20\%nanomica. (b) Crack propagation path through matrix (marked by arrow), crack bridging by mica ((c) and (d) marked by arrow), and (e) mica agglomeration and pull-out for HA-25\%nanomica composites.

In order to understand the dominant mechanism governing the fretting wear, topographical investigation of worn surface was carried out by SEM. The worn surface of representative HA-20\%NM is shown in Figure 7. The delamination and abrasive mode of material transfer are the main damage mechanism that can be observed. Moreover, the worn surface shows numerous microcracks which formed perpendicular to the fretting direction. The cracks propagate to the surface initiating the generation of wear debris in wear surface. Formation of wear debris and their displacement from contact surface at the time of fretting causes fluctuations in coefficient of friction which has been observed in Figure 5(a). Fu et al. [32] reported the COF of HA coating stable in between 0.7 and 0.8 whereas for titanium alloy COF is $0.6-0.7$. Their work demonstrated that the HA coating as well as Ti alloy shows delamination and abrasive mode of wear under unlubricated fretted condition.

The in vitro biocompatibility test of the optimized HA$20 \% \mathrm{NM}$ composite was conducted by immersing it into simulated body fluid (SBF). It elicits out whether the prepared composite is undergoing any chemical alteration after reaction. After putting it in SBF, chemical composition of dipped sample was analyzed by EDS. The surface microstructure of sample before and after soaking (Figures 8(a) and 8(c)) does not show any detectable microstructural change. It can be seen that both samples show uniform structure without any visible surface cracks. Furthermore, the compositional analysis also reveals similar results, presumably no chemical reaction of the composite with SBF (Figures 8(b) and 8(d)). Zhang et al. [33] reported that the biological behavior of biomaterials depends on the interaction between the simulated body fluid solution and biomaterial. Sample weight of the dipped one also does not show any weight loss after 60 days of immersion. This suggests that the addition of nanomica in HA matrix is stable in SBF for this duration. However, a detailed biocompatibility assessment of the newly developed composite requires the in vivo performance evaluation, which is not within the scope of the work reported here. 


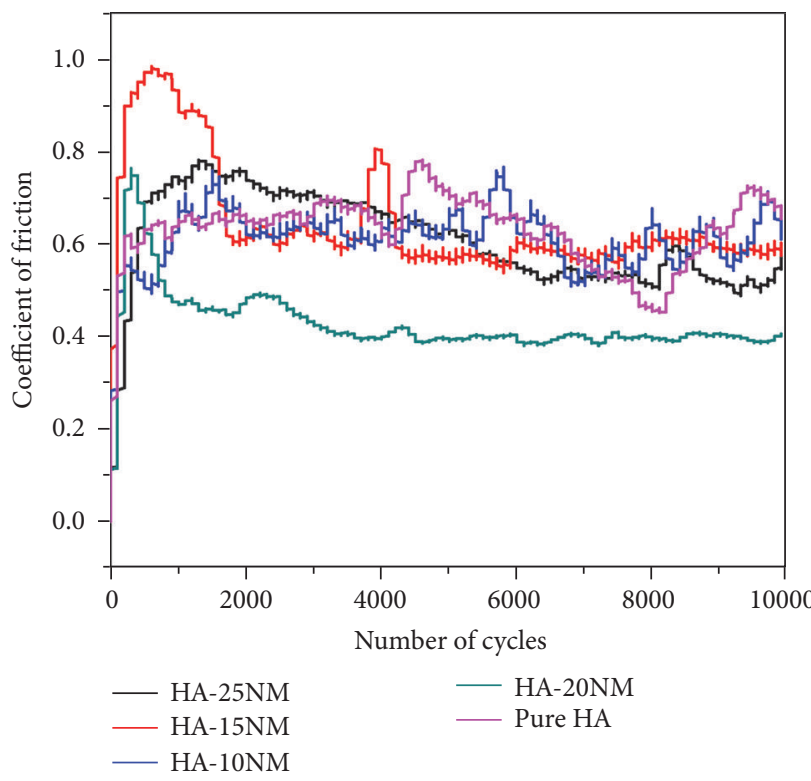

(a)

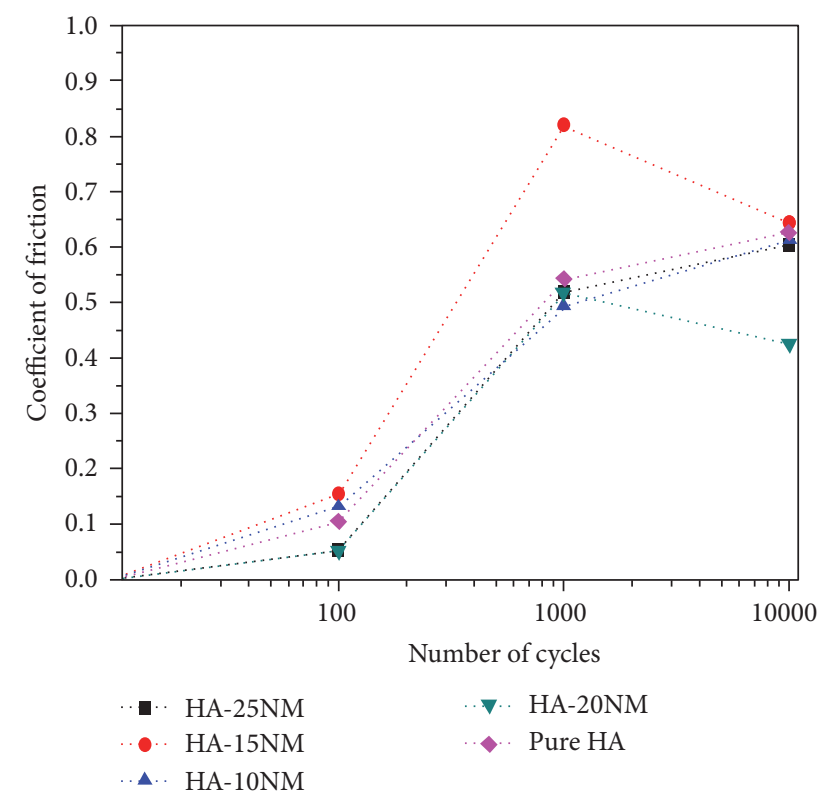

(b)

FIgURE 5: Plot of coefficient of friction (COF) with number of cycles for HA-NM composites ((a) in log scale (b)).

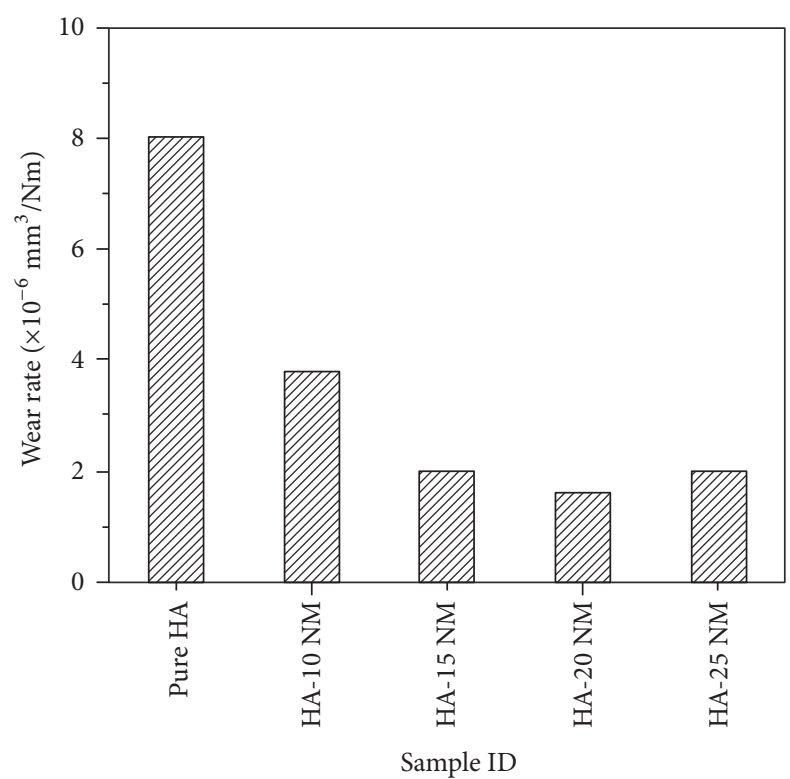

FIGURE 6: Measured values of wear rates of different samples under ambient condition.

\section{Conclusions}

Based on experimental results and discussions, the salient conclusions of the present research work can be summarized as follows:

(1) HA-nanomica composite was successfully prepared by mechanical milling and subsequent microwave sintering. With $20 \%$ dispersion of second phase optimum mechanical property was achieved. Observed

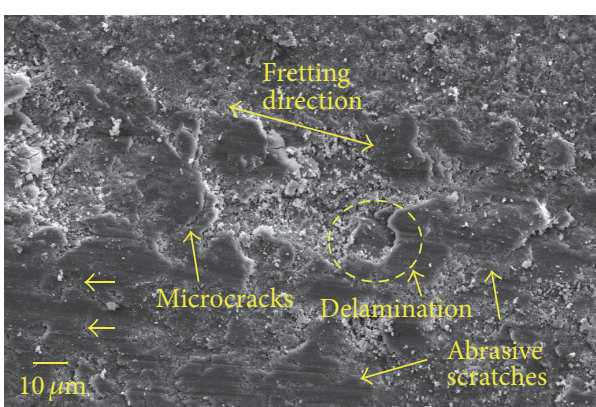

FIGURE 7: SEM image of worn surface of representative HA-20\%NM composite.

microhardness and indentation fracture toughness of representative HA-20\%NM was obtained $2.8 \mathrm{MPa}$ and $1.51 \mathrm{MPam}^{1 / 2}$, respectively.

(2) Porosity formation is due to different thermal shrinkage of HA and $\beta$-TCP, which forms during sintering by dehydroxylation of HA. SEM observation of the indent crack shows bridging, deflection, and pulling out of second phases which contributes towards hardness of the composite.

(3) At steady state value of COF is minimum ( 0.4) for $\mathrm{HA}-20 \% \mathrm{NM}$ and also minimum wear rate 1.6 $\times 10^{-6} \mathrm{~mm}^{3} / \mathrm{Nm}$., governing wear mechanisms are mainly delamination and abrasive mode of material transfer.

(4) Assessment of in vitro biocompatibility by immersing in SBF shows neither any weight change nor any chemical change (confirmed by EDS), which makes 


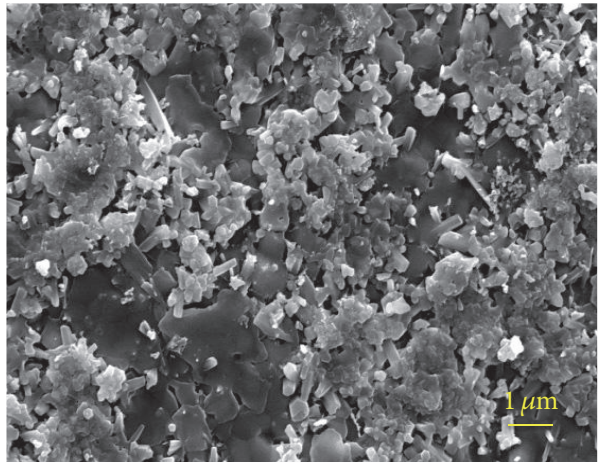

(a)

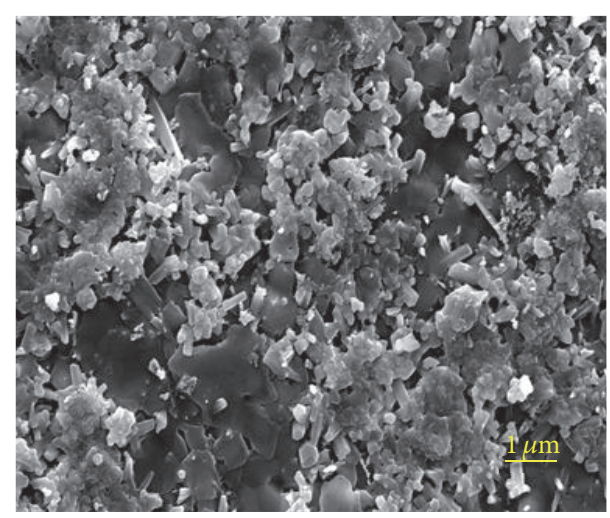

(c)

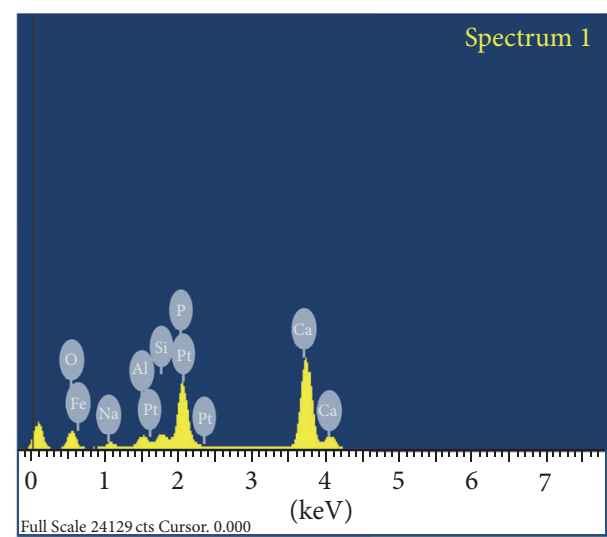

(b)

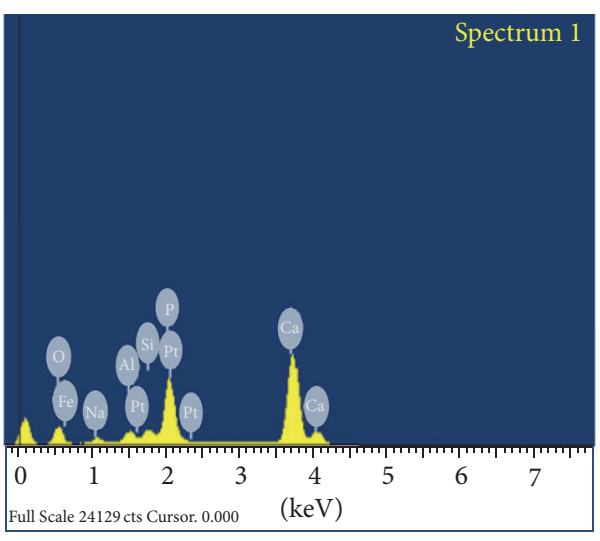

(d)

FIGURE 8: Surface morphology of representative HA-20\%NM composite (a) before immersion and (b) corresponding EDS (c) after 60 days immersion and (d) corresponding EDS.

it suitable for further in vivo investigation for precise investigation of its biocompatibility.

\section{Competing Interests}

The authors declare that they have no competing interests.

\section{References}

[1] S. M. Best, A. E. Porter, E. S. Thian, and J. Huang, "Bioceramics: past, present and for the future," Journal of the European Ceramic Society, vol. 28, no. 7, pp. 1319-1327, 2008.

[2] M. Vallet-Regí, "Ceramics for medical applications," Journal of the Chemical Society, Dalton Transactions, no. 2, pp. 97-108, 2001.

[3] H. Liang, B. Shi, A. Fairchild, and T. Cale, "Applications of plasma coatings in artificial joints: an overview," Vacuum, vol. 73, no. 3-4, pp. 317-326, 2004.

[4] M. H. Fathi and E. M. Zahrani, "Fabrication and characterization of fluoridated hydroxyapatite nanopowders via mechanical alloying," Journal of Alloys and Compounds, vol. 475, no. 1-2, pp. 408-414, 2009.

[5] W. Que, K. A. Khor, J. L. Xu, and L. G. Yu, "Hydroxyapatite/ titania nanocomposites derived by combining high-energy ball milling with spark plasma sintering processes," Journal of the European Ceramic Society, vol. 28, no. 16, pp. 3083-3090, 2008.

[6] Y.-M. Kong, C.-J. Bae, S.-H. Lee, H.-W. Kim, and H.-E. $\mathrm{Kim}$, "Improvement in biocompatibility of $\mathrm{ZrO}_{2}-\mathrm{Al}_{2} \mathrm{O}_{3}$ nanocomposite by addition of HA," Biomaterials, vol. 26, no. 5, pp. 509-517, 2005.

[7] I. H. Arita, D. S. Wilkinson, M. A. Mondragón, and V. M. Castaño, "Chemistry and sintering behaviour of thin hydroxyapatite ceramics with controlled porosity," Biomaterials, vol. 16, no. 5, pp. 403-408, 1995.

[8] R. Ramachandra Rao and T. S. Kannan, "Synthesis and sintering of hydroxyapatite-zirconia composites," Materials Science and Engineering C, vol. 20, no. 1-2, pp. 187-193, 2002.

[9] V. V. Silva, F. S. Lameiras, and R. Z. Domingues, "Microstructural and mechanical study of zirconia-hydroxyapatite $(\mathrm{ZH})$ composite ceramics for biomedical applications," Composites Science and Technology, vol. 61, no. 2, pp. 301-310, 2001.

[10] C. E. Wen, W. Xu, W. Y. Hu, and P. D. Hodgson, "Hydroxyapatite/titania sol-gel coatings on titanium-zirconium alloy for biomedical applications," Acta Biomaterialia, vol. 3, no. 3, pp. 403-410, 2007.

[11] G. Xiong, Y. Nie, D. Ji et al., "Characterization of biomedical hydroxyapatite/magnesium composites prepared by powder 
metallurgy assisted with microwave sintering," Current Applied Physics, vol. 16, no. 8, pp. 830-836, 2016.

[12] B. Singh, A. K. Dubey, S. Kumar, N. Saha, B. Basu, and R. Gupta, "In vitro biocompatibility and antimicrobial activity of wet chemically prepared Ca10-xAgx $\left(\mathrm{PO}_{4}\right)_{6}(\mathrm{OH})_{2}(0.0 \leq \mathrm{x} \leq 0.5)$ hydroxyapatites," Materials Science and Engineering $C$, vol. 31, no. 7, pp. 1320-1329, 2011.

[13] S. Nath, K. Biswas, and B. Basu, "Phase stability and microstructure development in hydroxyapatite-mullite system," Scripta Materialia, vol. 58, no. 12, pp. 1054-1057, 2008.

[14] Q. Wang, S. Ge, and D. Zhang, "Nano-mechanical properties and biotribological behaviors of nanosized HA/partiallystabilized zirconia composites," Wear, vol. 259, no. 7-12, pp. 952-957, 2005.

[15] A. Farzin, M. Ahmadian, and M. H. Fathi, "Comparative evaluation of biocompatibility of dense nanostructured and microstructured Hydroxyapatite/Titania composites," Materials Science and Engineering C, vol. 33, no. 4, pp. 2251-2257, 2013.

[16] S. Kalmodia, S. Goenka, T. Laha, D. Lahiri, B. Basu, and K. Balani, "Microstructure, mechanical properties, and in vitro biocompatibility of spark plasma sintered hydroxyapatite-aluminum oxide-carbon nanotube composite," Materials Science and Engineering C, vol. 30, no. 8, pp. 1162-1169, 2010.

[17] A. Kumar, K. Biswas, and B. Basu, "On the toughness enhancement in hydroxyapatite-based composites," Acta Materialia, vol. 61, no. 14, pp. 5198-5215, 2013.

[18] C. Richard, K. Hing, and H. P. Schreiber, "Interaction balances and properties of filled polymers," Polymer Composites, vol. 6, no. 4, pp. 201-208, 1985

[19] C. J. Marshal, R. Rozett, and A. C. Kunkle, "Effects of mica as a filler in polyolefins and PVC," Plastics Compounding, vol. 8, no. 7, pp. 69-74, 1985.

[20] R. T. Woodhams and M. Xanthos, Handbook of Fillers and Reinforcements for Plastics, Van-Nostrand, Princeton, NJ, USA, 1978, Edited by H. S. Katz and J. V. Milevski.

[21] S. Hatahira, "Sintered apatite bodies and composites thereof," Patent US 4,503,157, 1985.

[22] T. Yamamura, M. Tokuse, and T. Furushima, "Inorganic fiberreinforced ceramic composite material," Patent US 4,610,917; September 1986.

[23] I. J. McColm, Ceramic Hardness, Plenum Press, New York, NY, USA, 1990.

[24] T. Kokubo, H. Kushitani, S. Sakka, T. Kitsugi, and T. J. Yamamuro, "Solutions able to reproduce in vivo surface-structure changes in bioactive glass-ceramic A- $\mathrm{W}^{3}$," Journal of Biomedical Materials Research, vol. 24, no. 6, pp. 721-734, 1990.

[25] Y. Yang, K.-H. Kim, C. M. Agrawal, and J. L. Ong, "Interaction of hydroxyapatite-titanium at elevated temperature in vacuum environment," Biomaterials, vol. 25, no. 15, pp. 2927-2932, 2004.

[26] A. K. Dubey, G. Sitesh, S. Nath, and B. Basu, "Spark plasma sintering to restrict sintering reactions and enhance properties of hydroxyapatite-mullite biocomposites," Ceramics International, vol. 37, no. 7, pp. 2755-2761, 2011.

[27] S. Dasgupta, S. Tarafder, A. Bandyopadhyay, and S. Bose, "Effect of grain size on mechanical, surface and biological properties of microwave sintered hydroxyapatite," Materials Science and Engineering C, vol. 33, no. 5, pp. 2846-2854, 2013.

[28] Y.-M. Kong, S. Kim, H.-E. Kim, and I.-S. Lee, "Reinforcement of hydroxyapatite bioceramic by addition of $\mathrm{ZrO}_{2}$ coated with $\mathrm{Al}_{2} \mathrm{O}_{3}$," Journal of the American Ceramic Society, vol. 82, no. 11, pp. 2963-2968, 1999.
[29] D. C. Tancred, B. A. O. McCormack, and A. J. Carr, "A quantitative study of the sintering and mechanical properties of hydroxyapatite/phosphate glass composites," Biomaterials, vol. 19, no. 19, pp. 1735-1743, 1998.

[30] X. Zhang, G. H. M. Gubbels, R. A. Terpstra, and R. Metselaar, "Toughening of calcium hydroxyapatite with silver particles," Journal of Materials Science, vol. 32, no. 1, pp. 235-243, 1997.

[31] N. Arun Prakash, R. Gnanamoorthy, and M. Kamaraj, "Fretting wear behavior of fine grain structured aluminium alloy formed by oil jet peening process under dry sliding condition," Wear, vol. 294-295, pp. 427-437, 2012.

[32] Y. Fu, A. W. Batchelor, Y. Wang, and K. A. Khor, "Fretting wear behaviors of thermal sprayed hydroxyapatite (HA) coating under unlubricated conditions," Wear, vol. 217, no. 1, pp. 132-139, 1998.

[33] Q. Zhang, J. Chen, J. Feng, Y. Cao, C. Deng, and X. Zhang, "Dissolution and mineralization behaviors of HA coatings," Biomaterials, vol. 24, no. 26, pp. 4741-4748, 2003. 

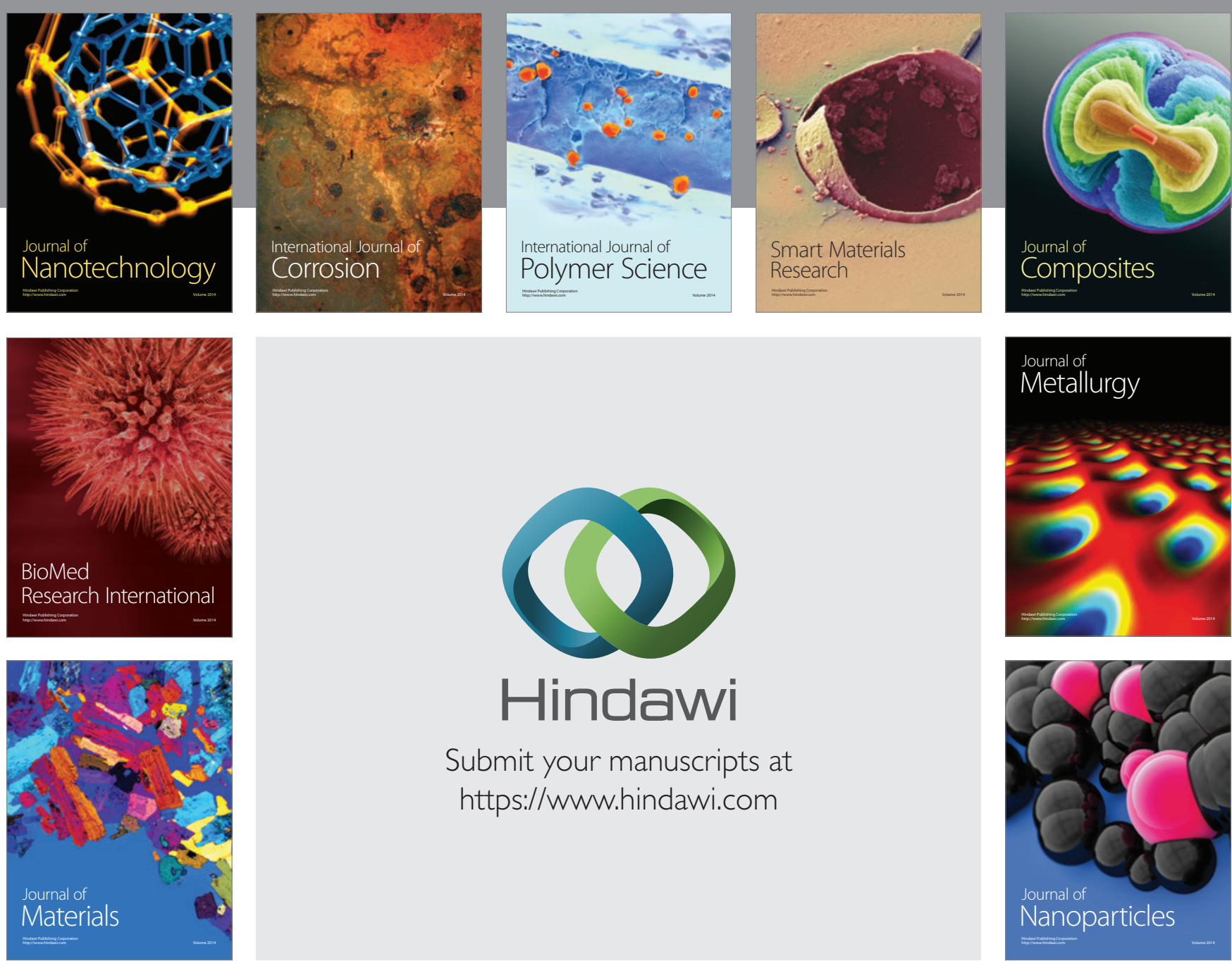

\section{Hindawi}

Submit your manuscripts at

https://www.hindawi.com

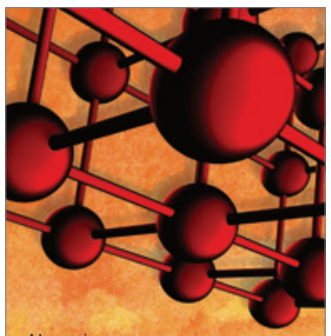

Materials Science and Engineering
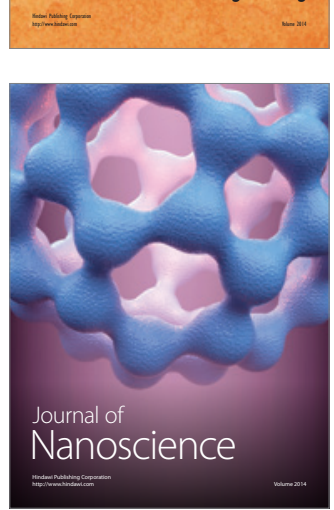
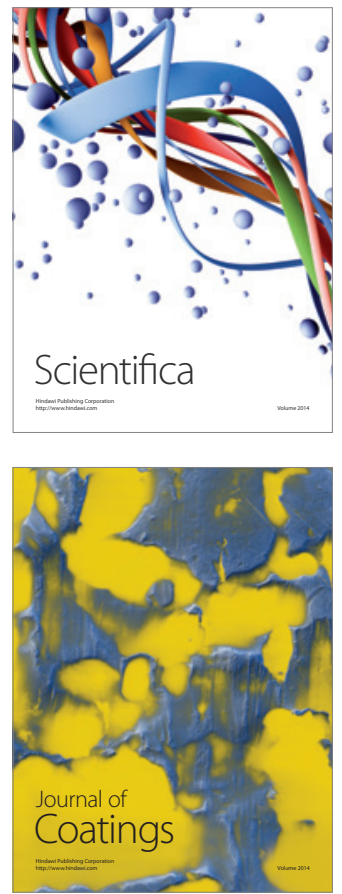
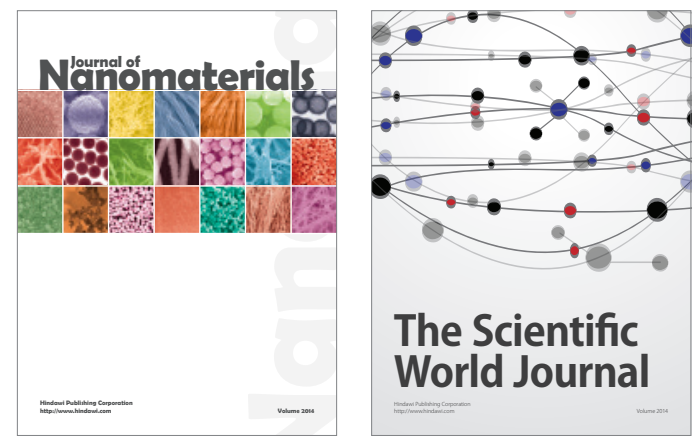

The Scientific World Journal
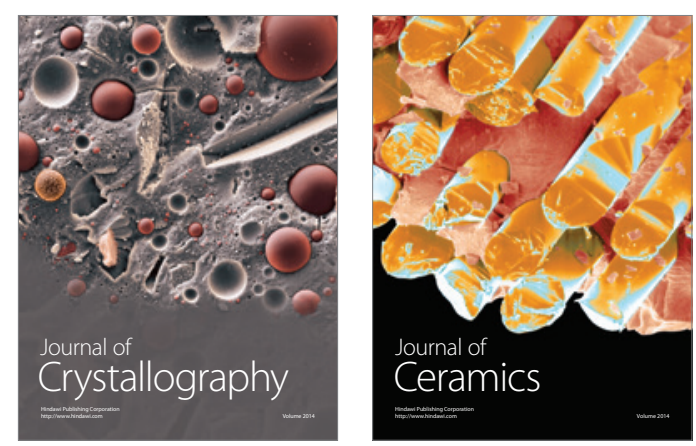
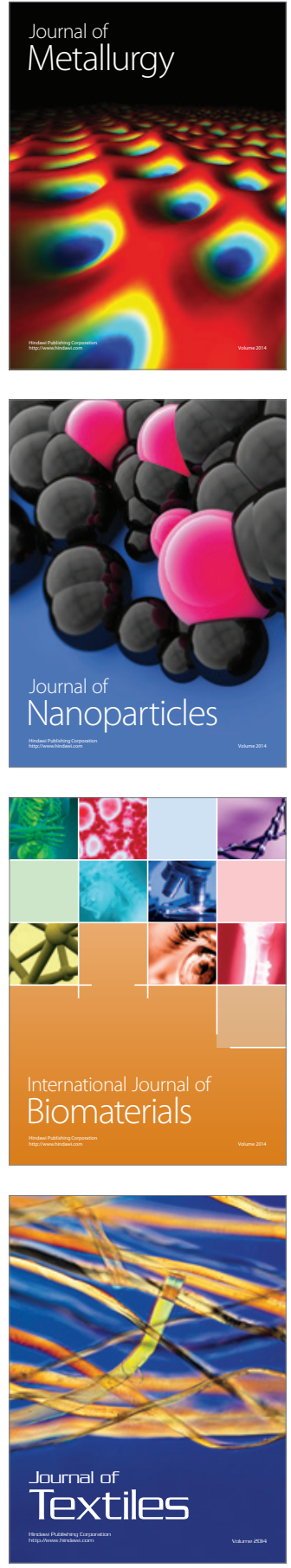